\title{
Desligamentos da crítica: psicanálise e reflexão sobre arte
}

\section{Unbinding critics: psychoanalysis and aesthetic thinking}

\author{
Gustavo Henrique Dionisio ${ }^{1}$
}

\begin{abstract}
Resumo
O artigo visa discutir a relação entre psicanálise e reflexão sobre arte, sob um recorte que toma alguns elementos da teoria do desligamento, concebida por André Green, articulando-a a certas proposições elaboradas pelo crítico e historiador da arte, Hal Foster, tendo a noção de real como conceito-chave da intersecção. Pode-se dizer, nesta afinidade criada no ensaio, que ambos tratam, cada um de maneira particular, de uma questão que se refere ao "real" (assim como fora concebido por Jacques Lacan) na experiência estética, ainda que, no caso de Green, não haja nenhuma referência direta ao psicanalista francês; sua teoria, no entanto, remete a um fator de regrediência que poderia ser articulado à pulsão de morte. Acessando o dispositivo psicanalítico a seu modo, e dela recolhendo o que lhe parece mais apropriado, diante do objeto (de arte) a ser investigado, Foster, por exemplo, avança tanto no campo da reflexão estética quanto no campo mais específico da psicanálise. Cabe mencionar que o trabalho do crítico refere-se, particularmente, às imagens pós-pop, observadas, sobretudo, na fotografia dos anos noventa. Assim, conceber esta intersecção estética e psicanálise nos permitiria lançar luz a novas possibilidades de leitura da obra de arte, tendo em vista um paradigma de psicanálise "não aplicada", o que, a meu ver, revela-se bastante apropriado, para entender a produção artística que costumamos chamar de contemporânea.
\end{abstract}

Palavras-chave: Psicanálise. Estética. Crítica de arte. Real. Metapsicologia

\begin{abstract}
This paper intends to discuss the relationship between psychoanalysis and aesthetic thinking under the prism of the "unbinding" theory - earlier conceived by the psychoanalyst Andre Green -, linking it to some theories proposed by Hal Foster, art historian and art critic, where we can find the lacanian "real" as the linking concept. One could say, in this linkage made here, that both authors are dealing, in a very particular way, with a question that refers to the theory of the real (as it was conceived by Jacques Lacan), even in the case of Green it is not referred directly; Green's theory, however, seems to discuss some kind of a regredience that could be linked to the death drive. Accessing the psychoanalytical dispositive, and using it as it is appropriated to the (art) object to be interpreted, Foster, for example, advances in both the field of aesthetic reflection and in the more specific field of psychoanalysis. It should be noted that Foster's reflection refers strictly to the post-pop images, observed mainly in the 1990's photography. Thus, I think that this intersection between aesthetics and psychoanalysis might allow us to shed some light on a new art reading possibility towards a "non-applied" psychoanalytical paradigm, which, in my opinion, seems to be an appropriate way to understand some of the contemporary art production.
\end{abstract}

Keywords: Psychoanalysis. Aesthetics. Art critic. Real. Metapsychology.

\footnotetext{
${ }^{1}$ Psicanalista. Prof. Assistente do Departamento de Psicologia clínica da Faculdade de Ciências e Letras, UNESP-Assis. Mestrado e Doutorado em Psicologia Social pelo Instituto de Psicologia da Universidade de São Paulo. Membro do Espaço Brasileiro de Estudos Psicanalíticos de São Paulo. E-mail: gustavohdionisio@gmail.com.
} 


\section{Da Crítica à Psicanálise}

No que tange ao estabelecimento de categorias a serem trabalhadas no campo conhecido como "crítica psicanalítica”, André Green figura, seguramente, como um autor dos mais relevantes. Para ele, sendo o crítico um "escritor-leitor", sua responsabilidade máxima é produzir uma "prática teórica", uma vez que, "em todos os planos em que pode ser exercida, [a psicanálise] é, fundamentalmente, sustentada por uma atividade crítica". Limitando um domínio que invoca a relação de inconsciente a inconsciente, o "método" do crítico-analista poderia ser denominado, "na falta de um termo mais adequado, de epistemologia subjetiva". Será obrigatório, a tal práxis, ter como metas o estudo e a interpretação das relações entre inconsciente e obra, exigência de uma escuta que é colocada à prova, dia após dia. Como paralela à atividade do crítico literário, a crítica de arte que segue este caminho se implica na apreensão de que, em toda obra, a "existência desse inconsciente está presente nas articulações temáticas, nas censuras dos textos, nos silêncios brutais, nas ruturas de tom e, sobretudo, nas manchas, nas escórias, nos detalhes aparentemente pouco importantes." (GREEN, 1994, p. 13, grifo nosso), nos elementos invisíveis e não ditos que servirão de objeto ao estudioso da matéria.

Aqui, esta noção de mancha se torna decerto paradigmática, de modo a fazer avançar a metáfora do psiquismo como tela. Entendida como "cartografia" do inconsciente, a mancha seria, mais precisamente, uma forma de mediação entre categorias analíticas e estéticas. Próxima da pictoriedade informe, por assim dizer, exige um poder de transformação no outro, da mesma maneira que, diante de uma obra ou texto, o psicanalista age como se se transformasse, ainda que não deliberadamente - como considera Green -, "pois é a transformação que se impõe a ele". Só assim, o interesse do trabalho se dispõe à dimensão de uma escuta que textos e obras proporcionam, transformando o ato de recepção estética em atenção flutuante do olhar.

Com isso, a recepção ultrapassa as articulações solitárias do espectador, por um tipo de relação que não é outra senão entre-dois (GREEN, 1994, p. 16; FRAYZE-PEREIRA, 2005, p. 410). Tendo estabelecido que as obras são o ponto de partida, e nelas restringindo a observação quanto ao que incitam de maneira associativa ${ }^{2}$ naquele que as contempla, uma grande abertura estará dada ao trabalho de desligamento (GREEN, 1994). Restará ao psicanalista, ouvir as tramas de texto/contexto, conforme as modalidades particulares de seu ofício.

Ao espectador cabe, portanto, desligar a obra; grosso modo, isso significa fazer a reestruturação de um traçado cujos indícios manifestam a atuação das elaborações secundárias, responsáveis por todo o acabamento da obra - o modelo, evidentemente, aproxima-se dos procedimentos clássicos de análise de sonho, com uma particularidade que talvez consigamos precisar: trata-se de um movimento psíquico de recepção estética no qual a tração se apresenta invertida. Em outras palavras, diante da imagem, o sujeito se vê obrigado a realizar um trabalho regrediente e não progrediente.

A escuta, uma vez desligada, coloca a imagem sob suspeita, pois sabe que os rastros foram disfarçados pela organização formal, exigência do acabamento artístico. $\mathrm{Na}$ qualidade de produtos secundários, imagem e fantasia (diferentemente do sonho) seriam fenômenos praticamente idênticos: sua diferença básica é que, no caso da fantasia, o

\footnotetext{
${ }^{2}$ Desejo apenas sublinhar que não pretendo trabalhar de modo analógico, mas associativo, tal como se dá em minha própria análise pessoal. Por associação livre entende-se, segundo o consagrado dicionário de Laplanche e Pontalis, uma ideia "que ocorre ao sujeito, aparentemente de forma isolada". O método associativo em psicanálise, que se difere da doutrina associacionista alemã, depende da experiência clínica, onde é possível observar que um resto mnêmico remete de maneira complexa a outros elementos numa determinada cadeia (LAPLANCHE; PONTALIS, 2004, p. 37).
} 
sujeito almeja uma racionalidade "sobre a qual a pessoa que fala baseia sua esperança de ser compreendida e reconhecida", conforme o princípio de "aceitabilidade semântica". Continuando com a ótica de Green (1994, p. 17-18), uma das principais características do texto literário - assim como de muita obras de arte modernas e pós-modernas e, por extensão, dentro ou fora do campo literário, a meu ver - é fazer "absoluta questão de ser inaudito". Assim, o objetivo do crítico se acerca, justamente, em desfiar os tecidos dessa secundariedade, para encontrar, "aquém dos processos de ligação, o desligamento encoberto pela ligação".

Em termos de "método", a metapsicologia do desligamento se resumiria à

\begin{abstract}
Passagem dos processos primários aos processos secundários: uma energia livre (não ligada) tendendo à descarga, utilizando os compromissos da condensação e do deslocamento, fazendo coexistir os contrários e indiferente à temporalidade, transformase em energia ligada cuja descarga é adiada, contida e limitada, obedecendo às leis da lógica e da sucessão temporal (GREEN, 1994, p. 17).
\end{abstract}

Ora, se, diante da elaboração secundária, o espectador consegue encontrar a lógica dos vestígios acidentais, que residem no nível do desejo e do substrato primário, é porque ele já se encontra em pleno trabalho clínico, no sentido daquilo que vai além da prática de gabinete. Já não se pode mais negar que, apesar de todas as advertências que ainda demarcam o atravessamento dos campos, qualquer estudo que se assuma "freudiano" deve reconhecer que as conquistas por ele alcançadas só fazem sentido se servirem ao pensamento clínico. Nessa medida, o estabelecimento de um limiar clínico nunca deixa de ser fundamental a qualquer psicanálise, por mais fora da clínica que se esteja se é que isto é mesmo possível de se estabelecer. Em outras palavras, "pensar psicanaliticamente implica escutar [...] as questões singulares e comoventes, isto é, ambíguas e por isso mesmo perturbadoras, daquele que sofre", como sugere João Frayze-Pereira (2005, p. 445, grifo nosso). Isto dito, refletir estética ou analiticamente significa - em ambos os casos e tendo em vista uma aproximação não forçada - dar forma a alteridades que, quase sempre de forma inarticulada, apresentam-se como experimentação sensível, localizando-se na cavidade que vai do não dizer ao dizer, do não ser artístico até a forma perceptível. Não obstante, nesse campo ilimitado que resulta do encontro eu-outro, não existem contratos de garantia.

Ainda que o olhar possa se perder na paisagem de traços primários do texto, a leitura flutuante faz com que estas unidades mínimas de sentido sejam registradas no inconsciente do espectador, sobretudo, na medida em que o fascínio produzido pela obra o comova no registro de seu consciente. E se, diante da obra, o analista conta apenas com o conjunto de suas próprias associações - e não com as do analisando -, logo, ele se transforma no analisado do texto (GREEN, 1994, p. 18). Assim, as interpretações que esta virada teórica consegue precipitar se legitimarão, somente a partir dos efeitos estéticos que a obra leva à consciência do "críticopsicanalista": trata-se, sem sombra de dúvida, "de uma experiência, pois ele revela abertamente as falhas de sua leitura e os limites de sua autoanálise." (GREEN, 1994, p. 18). ${ }^{3}$

\section{Da Psicanálise à Crítica}

Ora, se uma inversão desta ordem é, com efeito, exequível, e se existem obras que pressupõem a análise de quem as vê; então, o trabalho crítico

\footnotetext{
${ }^{3}$ Talvez, este aspecto permita que a ideia de desligamento seja também pensada em termos de pulsão de morte, como indicam Julia Kristeva (1997) e René Major (comunicação pessoal, janeiro de 2009). Para a autora, quando Freud sugere Thânatos, é exatamente disso que está falando: dé-liaison, força de retorno ao inorgânico.
} 
será sempre chamado a intervir. Nessa medida, as motivações presentes em The return of the real, livro que o crítico e historiador da arte Hal Foster publica nos anos 1990, dão provas de uma reflexão que merece destaque neste eixo de relações implicadas entre a estética e a psicanálise. Ao investigar o problema da "estranha temporalidade" inerente à concepção de vanguarda - temporalidade perdida, aliás, "em histórias da arte do século XX" - Foster (1996, p. x) teria conseguido ampliar a própria categoria de vanguarda, ao percorrer um trajeto que vai da experiência estética à experiência analítica. "Tal como a vanguarda recua ao passado", escreveria, bastante influenciado pelo Freud do "Homem dos Ratos", "ela, também, retorna do futuro, reposicionada de modo inovador com a arte do presente".

Alinhavada em suas publicações mais maduras, tal mudança paradigmática, cuja radicalidade é inaugurada em Walter Benjamin e depende claramente de sua dialética, supõe a necessidade de discutir, a partir dos eixos vertical e horizontal (isto é, diacrônico e sincrônico), como a categoria tradicional de vanguarda viria a se tornar insatisfatória, sobretudo, em função do surgimento de poéticas contemporâneas que a tematizam e a rediscutem programaticamente. Neste caso particular, cabe dizer que o problema se desenvolve praticamente em três décadas - de 1960 a 1990.

É claro que o historiador americano está se referindo à Teoria da Vanguarda, conforme proposta defendida por Peter Bürger, em seu mais reconhecido ensaio. Segundo Foster (1996, p. 208), existem certas nuances discursivas - determinadas pelos circuitos de produção e crítica de arte - que inauguram novas categorias de sujeito, da noção de outro da cultura e das transformações tecnológicas subsequentes, nuances que permitiriam relativizar a concepção histórica de vanguarda. Assim, nesta linha que conduz a história do moderno ao pósmoderno, não caberia presumir a existência de uma progressão horizontal. Para Foster, o eixo de seu desenvolvimento é ao mesmo tempo cíclico e descontínuo: a partir da articulação entre os diferentes discursos, revela-se uma concepção singular de temporalidade para cada uma destas "épocas"; trocando em miúdos, pode-se dizer que de trinta em trinta anos - isto é, conforme se estabelecem determinados ciclos econômicos do capitalismo tardio -, o espírito estético da modernidade acabaria exigindo reelaborações de seu passado, procurando, desse modo, saber, afinal, para onde ir.

Tal ressignificação crítica em torno do conceito de vanguarda foi, na verdade, inspirada, não obstante, como Foster não deixa de reconhecer, por uma intervenção em que o crítico Benjamin Buchloh aponta as condições que levaram ao estancamento histórico da concepção de vanguarda. Em consequência de um intenso debate com o texto de Bürger, é de fato Buchloh quem, a princípio, reconhece a necessidade de importar, da psicanálise, uma teoria da história que conseguisse satisfazer a complexidade do fenômeno de "pós-modernização" da arte. Para o adorniano Bürger, como se sabe, a noção de vanguarda teria morrido junto dos ismos do século XX. Na posição contrária e, assim como o Marx do 18 Brumário, Bürger insiste que, em termos de arte, tudo o que surgiu, após os movimentos do início do século, não seria muito mais do que mera imitação.

E é em função de julgar a categoria histórica de vanguarda como "deficiência crítica" que Buchloh (1986, p. 43) buscará o auxílio de Freud, e sua reação chegará às vias de fato: "Melhor que descartar quarenta anos de história da neovanguarda com a ingenuidade de um historiador da arte que limita seu campo e predetermina suas fronteiras", declara em "The primary colors for the second time", "talvez seja mais apropriado investigar as condições fatídicas de recepção e de transformação dos paradigmas da vanguarda". Ainda segundo Buchloh, o repertório de repetições acessado pela vanguarda contemporânea possui um conjunto de especificidades que impõe outra sistematicidade à análise. Ora, a presença de uma repetição na arte 
contemporânea visaria trazer à superfície algo que antes teria sido reprimido, assim como indicava, em outro circuito, as descobertas de Freud. Neste caso, o prefixo neo, antes de ser julgado como simples vontade novidadeira, sugere que alguma experiência passada carece de elaboração presente. Nas palavras de Buchloh (1986, p. 43),

Este esclarecimento deveria ser desenvolvido, a princípio, dentro da prática discursiva propriamente dita, e não por uma procura de recursos em categorias transcendentais como causalidade e determinação. Tampouco, pode-se elucidar a relação entre a vanguarda histórica e a neovanguarda, a partir de um propósito centralizado, o de um momento autêntico de originalidade, diante do qual todas as atividades subsequentes surgem como meras repetições.

Inspirado por estas conclusões, Hal Foster propõe, então, a concepção de parallax, procurando circunscrever, assim, uma teoria da história que abrangesse este movimento pendular da modernidade. Este seu procedimento, em linhas rápidas, "envolve o deslocamento aparente de um objeto causado pelo movimento real de seu observador. Esta imagem [parallax] enfatiza que nossos enquadramentos do passado dependem de nossas posições no presente", assim como as posições de agora serão redefinidas por meio de novos enquadramentos. Desse modo, o presente, tal como Benjamin adiantara em suas Teses sobre a História, é uma somatória de memórias do passado com as prospecções de um futuro por vir.

No que concerne à especificidade do campo psicanalítico, Foster está sugerindo um resgate da teoria freudiana do trauma, cuja temporalidade se nos revela bastante característica: Nachträglichkeit é o conceito utilizado pelo psicanalista para definir a ressignificação que a histérica faz da sedução infantil da qual teria sido vítima. Dessa maneira, a condição de reflexividade do observador sempre estará demarcada, seguindo esta teoria de Foster via Freud, por uma força de "retroação temporal" (que no inglês se traduziu por deferred action, implicando o caráter diferencial da repetição). "Em Freud, um evento é registrado como traumático, apenas através de um evento posterior que o recodifica retroativamente", ou seja, por meio de uma "ação diferida" (FOSTER, 1996, p. xii). ${ }^{4}$

"Empresto a noção de ação diferida de Freud, para quem, a subjetividade, nunca dada de uma vez por todas, é estruturada numa série de antecipações e reconstruções de eventos que, por natureza, são geralmente traumáticos: chegamos a ser quem somos apenas na ação diferida." (FOSTER, 1993, p. 5).

A partir de um processo dialético como esse, modernismo e pós-modernismo podem ser "compreendidos, senão constituídos, de maneira análoga”. Daí não se exclui, por certo, que o significado mais amplo de vanguarda seja atravessado pelo mesmo entrecortar de antecipações futuras e reconstruções do passado. "Cada época sonha a próxima”, lê-se na sua conclusão benjaminiana para The return of the real, "mas, ao fazê-lo, revisa a que lhe foi anterior; assim como uma época conduz à próxima, esta compreende a anterior" (FOSTER, 1996, p. 218). De acordo com a dinâmica temporal, a ideia de que exista um presente "em si" se torna inútil, assim como o marco sincrônico funcionaria apenas como uma ferramenta de esquematização, pois, a rigor, o presente seria uma mistura de tempos. E, como pensava Freud (1996, p. 6), neste sentido, a dimensão do sexual sempre vem antes ou depois do que deveria vir, e nunca no momento "presente". Por essa razão, a consciência que se tem de um determinado período "não apenas surge depois do

\footnotetext{
${ }^{4}$ A tradução de Nachträglich por deferred action - opção feita pela Standard Edition das obras completas de Freud - é motivo de controvérsia. Laplanche e Pontalis sugerem que traduzir por "ação diferida" faria perder seu caráter dinâmico, pois seria entendida como uma "descarga retardada", o que não condiz à aplicação freudiana. Para Freud, haveria, nesta posterioridade (sugestão desses autores), um verdadeiro processo de elaboração.
} 
fato": ela, "também, está sempre em parallax" quer dizer, funcionando segundo o processo de retroação.

Esta noção de "posterioridade", (conforme a tradução proposta para Nachträglichkeit por Laplanche e Pontalis), não possui; entretanto, uma definição rigorosa ou qualquer teoria de conjunto. Além disso, em psicanálise, a temporalidade anda sempre de mãos dadas com a tese da causalidade psíquica, onde de fato recai o maior conjunto de investigações teórico-clínicas. Em suma, a tese defende que certos acontecimentos presentes contingências mais ou menos significativas - teriam o poder de ressignificar experiências anteriores, no geral traumáticas, ou conseguiriam dotarlhes de uma "eficácia psíquica", pela via de uma interpretação, por exemplo.

Além de alargar o conceito de história, a categoria de "posterioridade" ainda acabaria ampliando os limites da própria reflexão estética - é o que Foster almeja fazer, com relação às poéticas que investiga. A psicanálise proporcionou-lhe a compreensão de que o passado que retorna não é um passado qualquer: se a repetição deixa de ser entendida apenas como farsa, justificando, portanto, sua presença enquanto procedimento de criação; então, as poéticas de neovanguarda teriam o direito de exigir, ao exercício da crítica, novas interpretações.

\section{Cinismo e Falsidade?}

A coisa repetível pode ser muito variável, conforme as singularidades em jogo, e é mesmo preciso "distinguir a repetição da coisa repetida" (ZYGOURIS, 1999, p. 20). Nem por "referência" nem por "simulacro", em The return of the real, Foster sugere uma terceira via de leitura para a pop art americana dos anos 1960, objeto de seu estudo. ${ }^{5}$ Esta posição evita tanto o caráter temático das interpretações, ou seja, aquilo a que se assiste, na melhor das hipóteses, com os ensaios em que Thomas Crow faz "sentimento e política" andarem lado a lado, quanto à rotulação de superficialidade que pensadores pós-estruturalistas como Barthes, Baudrillard, Foucault e Deleuze viriam delegar àquela poética.

Ainda que as duas referências tenham falado de seu presente de maneira indireta, a partir da "reconstrução de momentos passados" combinada à "antecipação de momentos futuros", tampouco, teriam deixado de se revelar insuficientes (FOSTER, 1993, p. 7). A propósito, a designação de "arte como simulacro" ou como "coleção de citações" fora bastante disseminada no início dos anos oitenta, sobretudo, após o surgimento da noção de "transvanguarda" cunhada pelo crítico e curador italiano Achille B. Oliva. Todo programa de arte que vise à apropriação do passado se tornaria figura central na discussão estética contemporânea, e é diante desses procedimentos pop e pós-pop que a reflexão de Foster procura um espaço para habitar. Enquanto a leitura referencial tenderia ao método relacional, fazendo associações entre a arte pop e o mundo da moda, a cultura gay ou o universo televisivo das celebridades, a interpretação pela via do simulacro não aposta na presença de quaisquer níveis de profundidade ou de interioridade subjetiva nos trabalhos. Não foram poucos, os críticos que condenariam as imagens, no geral, pela acusação de destituição de senso histórico ou pelo registro de uma arte cínica, sem substância.

A referencialidade, por outro lado, também, não melhorou o estado de coisas: "A maioria das descrições a respeito da arte de suporte fotográfico do pós-guerra divide-se, de algum modo, nessa linha", conclui o crítico, na "imagem como referência ou como simulacro" (FOSTER, 1996, p. 128). De modo mais preciso, Foster sugere que

${ }^{5}$ Foster refere que seu trabalho se concentra especialmente nas imagens de "Death in America", expostas, naquela década, por Andy Warhol em Paris. 
A compreensão empática - ou mesmo a engajada - de Warhol é uma projeção, não mais que a superficial, de um Warhol passivo, ainda que esta projeção viesse dele mesmo: "Se você quer saber tudo sobre Andy Warhol, apenas olhe para a superfície de minhas pinturas e filmes, e lá estou eu. Não há nada por detrás". Ambos campos perfazem o Warhol que eles querem, ou dão o Warhol que merecem; não há dúvidas de que assim o façam. E nenhuma das projeções está errada. Acredito que as duas são persuasivas. Mas não poderiam estar ambas corretas... ou podem? Podemos ler as imagens de "Death in America" como referenciais e simulacrais, conectadas e desconectadas, afetivas e desafetadas, críticas e complacentes? Acredito que devemos fazê-lo (FOSTER, 1996, p. 130).

Revelada a estratégia empobrecedora do "ou ou", examinemos mais a fundo os pormenores: se o vazio na sentença "I want to be a machine", de Warhol, pode ser colocado em dúvida pelo caráter desejante do I want, é porque este buraco deve ser entendido como trauma e não como esvaziamento. Ao experimentar o choque de, também, ser máquina, assombro aproximado daquilo que "paralisa o mecanismo associativo do espectador", segundo Walter Benjamin (1994, p. 107), é como se no sujeito se instalasse algo que lhe serviria de mecanismo mimético-defensivo. Por um lado, quando confessa qual é seu almoço predileto durante os últimos vinte anos - "o que mais, além de Sopa Campbell's"? -, o artista estaria metaforizando o caráter de “compulsão à repetição" de sua própria vida; por outro, no entanto, também, estaria metaforizando a compulsão de sua própria arte. Em outras palavras, a cada vez que se adere a uma sociedade em que produção e consumo se tornam elementos seriais, mais exposta se revela a estrutura compulsiva desta mesma sociedade.

Declarar o "automatismo, até mesmo seu autismo", em escala cultural seria o horizonte de realização do mais famoso artista pop: "Se você não pode com eles, junte-se a eles", diria ironicamente. Nessas circunstâncias, trata-se de pensar em que medida o traumático e o compulsivo repõem a questão formal da repetição na imagem contemporânea. Assiste-se, neste contexto, tanto ao esgotamento da significação quanto a uma espécie de artifício de defesa contra o afeto que guiariam Warhol (e outros da mesma linhagem) até o final de sua carreira (FOSTER, 1996, p. 131). Esse vazio autístico/afásico de significância é marcado por um aglomerado de caracteres psicológicos, acessados, inclusive, por quase toda a arte, desde Duchamp: a obsessão pelo comportamento repetitivo e pelo funcionamento maquínico, a crise da noção de identidade como categoria fixa, que passa a ser vivida como perda de sentido referencial - quem é o "eu" e quem é o "tu" nas sentenças duchampianas? -, assim como o narcisismo intrínseco às videomedias denunciado por Rosalind Krauss, e daí por diante.

Antes, porém, seria preciso ter em mente que o niilismo capitalista de Warhol é parte integrante de sua poética. E as performances dele decorrentes se aproximam, de maneira quase infantil, ao acting out: "há um sujeito 'por detrás' desta figura de não subjetividade que a apresenta como uma figura"; do contrário, "o sujeito traumatizado seria um oximoro para o qual não há um sujeito presente em choque" (FOSTER, 1996, p. 131). Com isso, não se poderia dizer que o fascínio que a pop-art suscita no espectador possui um caráter de certo modo "panóptico"? Não haveria ali, por detrás do vazio, o anão - o artista - que manipula o "boneco" da imagem, como Benjamin (1994) bem indicara?

\section{"Experiências" do Real: Angústia e Trauma}

Por outro lado, "realismo traumático" é a indicação que Foster propõe para elaborar este não lugar da temporalidade estética atual, o lugar do anão que vive no interior do autômato. Em analogia ao funcionamento do aparelho psíquico, o real, antes reprimido pelo pós-estruturalismo pósmoderno, retornaria, agora, sob a forma da ferida ou do trauma, reedição permanente da experiência sofrida. Warhol, por exemplo, como lembra Foster, nunca deixou de declarar seu apreço pela mesmice, sobretudo, em função da sua alta capacidade para esvaziar o sentido da imagem. E, conforme Freud já havia estabelecido, uma das principais atribuições 
da repetição é fazer com que o evento traumático retomado em sonhos, ações, imagens e sintomas - se apague, no presente, por meio da sua integração na economia simbólica.

Contudo, as repetições do artista americano não teriam a mesma função de restauração, pois não dizem respeito ao "domínio do trauma. Mais do que o paciente libertado do objeto no luto", elas sugerem "uma fixação obsessiva no objeto da melancolia" (FOSTER, 1996, p. 131-132). A saída não é tão simples, e o exemplo da acumulação de "Marilyns" não poderia ter sentido mais profundo. Além de reproduzir os efeitos traumáticos, na verdade, a série os produz. Ora, tais repetições carregam contradições radicais no seu interior e não pressupõem, a priori, grandes elaborações... Se, por um lado, a dialética da imagem apropriada oferece uma proteção diante da significação traumática, por outro, também, proporciona uma abertura das defesas contra ela: "uma defesa contra [um] afeto traumático e a sua produção".

Para, então, pensar o trauma, Foster decide se lançar ao dispositivo psicanalítico lacaniano. Com a recusa de uma postura reducionista e munida da crítica à incompetência das leituras anteriores (temático-referencial e iconográfica), sua intervenção alude a afinidades insuspeitadas entre o surgimento da arte pós-moderna e a teoria psicanalítica do olhar (regard ou gaze, no original francês e na tradução inglesa, respectivamente) desenvolvida no interior do "retorno a Freud" feito pelo famoso psicanalista.

Cabe assinalar, neste contexto, que Lacan pronunciava o seminário sobre "Os quatro conceitos fundamentais da Psicanálise", de onde saiu a teoria sobre o olhar, à mesma época em que Andy Warhol expunha uma série de trabalhos em Paris (estamos em 1964). O episódio é apenas peculiaridade, sem dúvida, pois, "diferentemente da teoria do simulacro de Baudrillard e companhia, a teoria do trauma de Lacan não é influenciada pela arte pop", tal como o próprio Foster (1996, p. 132) esclarece, e sim pelo surrealismo francês, passagem notória na história da arte e da psicanálise. Ainda assim, se vale dizer que "Os quatro conceitos..." não foram influenciados diretamente pelo trabalho de Warhol, tampouco, se pode afirmar, de maneira categórica, que certas imagens criadas pelo artista não teriam sido atravessadas pela teoria lacaniana. É bem pouco provável que eles, um dia, tenham se encontrado; contudo, a "unidade conceitual" das obras permanece, no mínimo, como um pano de fundo para os dois casos (LIU, 2002). Ora, este seminário, que inaugura toda uma discussão psicanalítica sobre o olhar, adentrou de maneira inegável o circuito das artes, servindo, particularmente, ao minimalismo e à arte conceitual. ${ }^{6}$

$\mathrm{Na}$ ocasião, Lacan procurava definir a noção de trauma em termos de um encontro perdido com o real; com isto que Lacan costumava definir como "o que insiste em não se escrever”. E, por não se consumar, cabe sublinharmos, o desencontro produz no sujeito um impulso de repetição. Repetir, no entanto, não é o mesmo que reproduzir (em psicanálise): em seu domínio, a repetição inconsciente funciona conforme a estrutura de um "retorno em espiral". Uma premissa como essa permite a Foster a compreensão de que a "repetição, em Warhol, não é uma reprodução, no sentido de representação (de um referente) ou simulação (de uma imagem pura, um significante apartado". Uma vez perdido, o encontro com o real nunca pode ser representado; e, se é o caso, acaba sendo vivido como repetição porque sua presença "serve para exibir o verdadeiro entendimento do traumático", ou melhor, "serve para dar forma ao real entendido como traumático.” (FOSTER, 1996, p. 132).

\footnotetext{
${ }^{6}$ No campo psicológico, ainda hoje, a questão do olhar é tratada mais frequentemente pelas correntes behaviouristas, psicofísicas ou gestaltistas.
} 
Embora esteja para além dela, o real pode ser encontrado durante a atividade onírica. No sonho, como se sabe, a perda do objeto é experimentada por meio da figurabilidade. ${ }^{7}$ Ora, apenas no sonho, o real pode ganhar uma forma - única por sinal -, justamente porque, sonhando, o sujeito não vê. Assim, o sonho no qual Freud diz "Pai, não vê que estou queimando?" seria, nesta perspectiva, um dos resultados mais ilustrativos da análise da perda. "O sujeito não vê no que isso vai dar", comenta Lacan a esse respeito; "ele pode, até mesmo oportunamente, se destacar, dizer para si mesmo que é um sonho, mas não poderia, em nenhum caso, se apreender dentro do sonho à maneira como, no cogito cartesiano, ele se apreende como pensamento" (LACAN, 1998, p. 76). No que tange à experiência estética ainda recente, Slavoj Zizek considera que o sonho seria o "paradigma simbólico" que contorna a passagem da modernidade à pós-modernidade: para ele, o paradoxo que a caracteriza é o da incompatibilidade entre simbólico e gozo. O que o sonho de Freud indicaria, em termos de verdade inconsciente, é o fato de que o pai não consegue ver que há um outro gozando, ao invés dele.

Se se considera, nesta ótica, que o sonho seja um locus privilegiado para a experiência psíquica com o real, nada mais adequado que retornar, como função complementar, a este sonho que teria sido o mais repetidamente interpretado, ao longo de toda a história da psicanálise. Ao figurabilizar a injeção de trimetilamina a ser aplicada em Irma, Freud nos ofereceu um exemplar princeps do contato com aquilo que, anos mais tarde, Lacan viria a chamar de real, ainda que a principal característica do real seja, porém, nunca se deixar interpretar em definitivo; é o que assegura sua existência perene.
No sonho da injeção de Irma, portanto, Freud não escapa simplesmente do inconsciente ou do real do desejo de Irma: ampara-se sobre eles. Esta é a razão pela qual a psicanálise pode reivindicar encontrar-se no inconsciente e no desejo da mulher, precisamente, porque registra, com rigor, sua inacessibilidade [...]. É em sua recusa a interpretá-los que a psicanálise os mantém (LACAN, 1998, p. 30, grifo nosso).

No decorrer da experiência com o real, "alguma coisa" de ordem psíquica pode vir a atravessar, isto é, "algo" deve produzir um corte: este algo - é, com efeito, o máximo que se pode dizer a seu respeito invade o sistema e instala uma ruptura na série de repetições. Já essa ruptura, de sua parte, encontrase "menos no mundo e mais no sujeito - entre a percepção e a consciência de um sujeito tocado por uma imagem" (FOSTER, 1996, p. 132). O princípio a que Foster se refere, nesse momento, é o da Tycke ${ }^{8}$ aristotélica, situação que dá forma às modalidades de encontro e desencontro entre sujeito e objeto, conforme retomado por Lacan.

Trata-se de um preceito com três faces. Em primeiro lugar, quando ganha valor simbólico, o objeto se transforma em Agalma; no caso contrário, torna-se Automaton, que é a modalidade de repetição característica do sintoma e, portanto, ancorada pelo recalcamento (Zwangswiederholung). Mas é somente na terceira opção que o encontro entre sujeito e objeto pode se dar pela via do real, isso que escapa ao simbólico e que instaura a confusão entre o interior e o exterior. O real está, por conseguinte, para além do sintoma. Nestes termos, tiquê seria, então, o encontro original com o real, ou melhor, é o acidente que nos leva ao seu encontro. Fazer uma análise representa, nessa perspectiva, uma das experiências mais próximas do real. Enquanto tiquê, o real está além e, ao mesmo tempo, por detrás "do autômaton", ou

\footnotetext{
${ }^{7}$ Para um bom entendimento desta categoria, remeto o leitor ao livro de César Botella (2007).

${ }^{8}$ Um equivalente para a Tycke seria, talvez, a noção de punctum desenvolvida por Roland Barthes em $A$ Câmara Clara, que, em linhas gerais, seria o efeito singular que um determinado conteúdo da obra pode vir a provocar no espectador.
} 
seja, "do retorno, da volta, da insistência dos signos aos quais nos vemos comandados pelo princípio do prazer" (LACAN, 1998, p. 56).

\section{Repetir, Recordar... Elaborar?}

A essa altura, já se pode reconhecer as garras do tigre. O encontro aí sugerido supõe a estrutura da repetição desenvolvida por Freud nos estudos sobre a histeria, categoria que se tornaria cara ao crítico Hal Foster: Nachträglichkeit. Na condição psíquica, todo encontro se remete a uma falta - "o encontro enquanto que podendo faltar, enquanto essencialmente faltoso", segundo Lacan - e, nesta lógica, à própria conjuntura do traumático. É o que faz como que entendamos melhor o que significa, em termos práticos, a função da "ação diferida" mencionada momentos antes. $\mathrm{O}$ trauma se configura na conjuntura de um après-coup que surge de outro modo. No tocante ao psicanalítico, tais esclarecimentos possuem uma importância e tanto: ao contrário do que insinuavam (ou ainda insinuam) certas acusações de determinismo, o que Freud pretendia demonstrar é que existe uma alternativa concreta para a vulgata da "fatalidade" psíquica dirigida à psicanálise, o que não se deve confundir com sobredeterminação psíquica. A profundidade da entrada em análise certifica esta constatação de maneira ainda mais concreta: a escuta clínica consegue verificar o quanto um sujeito é capaz de "modificar" seu passado, em função das experiências psíquicas que vive depois. Existe, para Freud, toda uma amplitude de reinscrições, novas configurações que serão feitas quase que obrigatoriamente ao longo de uma análise. Se toda lembrança é de fato encobridora, assim, ela é porque houve algum tipo de reorganização posterior. Em outras palavras, trata-se de um vai-e-vem temporal que conduz, afinal, à elaboração psíquica.

Tornou-se, também, lugar comum, à crítica ou à historiografia, renunciar às conclusões da teoria psicanalítica, na medida em que ela definiria a história atual do sujeito como causada por uma infância extática. Nestes moldes, o destino humano estaria para sempre aprisionado aos momentos iniciais da vida mental, o que restringe - ou melhor - impossibilita o espaço de intervenção terapêutica. Ora, esta censura se aproxima de uma crítica à "psicanálise aplicada", e teria os devidos méritos, se não fosse pelo esforço do próprio Freud: como ele indicou, não são todas as experiências passadas que virão demandar uma eficácia psíquica ulterior. A ressignificação só é exigida para aquilo que permaneceu, lá atrás, impossível de ser integrado em um conjunto de "homeostase". É nesse ínterim que nasce o trauma e é por sua razão que se demanda a exigência de um certo "tamponamento" psíquico, isto é, um tipo de obturação que deve ser administrado pelo princípio de prazer em virtude do trauma - conceito que exige uma última precisão.

No entendimento de Laplanche (1989, p. 88), ainda restariam dois aspectos essenciais à condição traumática. Em primeiro lugar, não basta que alguma coisa do exterior simplesmente chegue à "criança, para que funcione como elemento de trauma e sedução". Em termos quantitativos, para que o trauma se instale, é necessária uma "contribuição externa" que, ao invadir a organização psíquica, provoca uma estimulação "demasiada forte para que a criança seja capaz de ligá-la". Do ponto de vista qualitativo, de maneira complementar, haveria uma "inadequação entre, por um lado, as capacidades de elaboração da criança nesse momento, o equipamento intelectual que ela tem à sua disposição, e, por outro, o nível do problema que se lhe apresenta". Cabe ressaltar, além disso, que os contornos do trauma são sempre mediados qualitativamente pelo desejo e pela fantasia, "na medida em que a fantasia nunca é mais do que a tela que dissimula algo de absolutamente primeiro, de determinante na função de repetição" (LACAN, 1998, p. 61). No que concerne ao psíquico, real e realidade se distinguem, e esta peculiaridade se torna, com efeito, crucial. A sedução pela qual a histérica fora submetida não é uma experiência 
ipsis literis, e isso Freud cansou de afirmar, depois de fazer correções em sua teoria: a lembrança da sedução, traumática por excelência, tende muito mais à fantasia do que ao acontecimento em si.

\begin{abstract}
A esta exigência respondem esses pontos radicais no real que chamo de encontros, e que nos fazem conceber a realidade como unterlekt, untertragen, o que em francês se traduziria pelo termo mesmo, em sua soberba ambiguidade na língua francesa, de souffrance. A realidade está lá en souffrance, lá esperando (LACAN, 1998, p. 57).
\end{abstract}

Mas, afinal, em que medida, este desvio nos pode auxiliar? Ele indica, ao menos, que tanto em Freud quanto em Lacan se pressupõe o desencontro na relação entre eu e outro, entre sujeito e objeto ou entre mundo interno e mundo externo (para, também, usar um vocabulário mais kleiniano). E ainda pode ser, além do mais, que este conflito encaminhe ao fator de precipitação do traumático na experiência com o real. Em termos plásticos, se o trauma discutido por Foster pode manter seu sentido, seja ele estético ou clínico, é porque se remete a uma estrutura de funcionamento muito específica: a infinidade de possibilidades contida no vasto terreno da criação artística.

Retornando ao campo da crítica, Foster sugere que, ao olharmos as imagens que Warhol produziu em Ambulance Disaster, por exemplo, nas quais vemos o retrato de um acidente com ambulância em dois planos", assistimos a verdadeiros "estouros" ("popping", para remeter às suas próprias palavras) que, embora não sejam detalhes muito peculiares, fornecem uma equivalência visual dos encontros perdidos com o real. É pouco dizer que tais estouros sejam acidentais; eles configuram, além disso, operações automáticas, tecnológicas e repetitivas, de maneira a serem introduzidas no inconsciente ótico contemporâneo. Seu aspecto acidental conduz, à primeira vista, a um efeito de choque, cujas consequências, aliás, serão vistas depois. Ainda assim, este procedimento de repetição pode ir além e "produzir uma segunda ordem de trauma, no caso, ao nível da técnica, onde o punctum quebra a cena e permite o real a empurrar" (FOSTER, 1996, 136).

Não se exclui a presença dos afetos que é aí originada: inequívoco é o preço de angústia cobrado pelas imagens do real. Em termos fenomênicos, por exemplo, elas exercem o paradoxo de serem videntes não visíveis. Isso significa dizer que, embora não o vejamos, seremos vistos pelo real. Mas o real não seria aquele que, ao olharmos, sempre lá está, olhandonos de volta? Se é o caso, esta reflexividade é indireta porque produz restos de... nada. Em outras palavras, viver a experiência com o real equivaleria a carregar as marcas da pulsão de morte. De acordo com Foster, as "fotografias de acidente" feitas pelo mais famoso artista pop americano indicam algo desta ordem de experiência. Ter a prova de que " sonhar na era da televisão, Life e Time" é apreender o que significa ter pesadelos análogos aos das pessoas vítimas de trauma que se preparam "para desastres que já aconteceram”. O mérito de Warhol, neste contexto, é nos propor quais são as múltiplas repetições que a recepção destas imagens suscita. Assim, Wiederkehr - o "retorno de um encontro traumático com o real, algo que resiste ao simbólico", que é a concepção que Lacan opôs à Wiederholung - se traduz pelo retorno do sintoma, isto é, algo recalcado que não consegue sair do lugar (FOSTER, 1996, p. 138).

Ainda, de acordo com Hal Foster (1996, p. 136),

\begin{abstract}
Nesse sentido, diferentes tipos de repetição estão em jogo em Warhol: repetições que se fixam no real traumático, que o exibem, que o produzem. E essa multiplicidade ilustra o paradoxo não apenas de imagens que são afetivas ou desprovidas de afeto, como também de espectadores que não são nem integrados (que é o ideal para a maior parcela da estética moderna: o sujeito composto pela contemplação), nem dissolvido (que é o efeito de muito da cultura popular: o sujeito entregue às intensidades esquizoides do signo-mercadoria).
\end{abstract}

${ }^{9}$ Foster destaca, nesta cena, não a imagem trágica da morte causada pelo acidente, mas a faixa branca colocada no rosto da personagem morta. Para ver a obra: http://warholprints.com/andy-warhol-ambulance-disaster-2/ 
Para concluir, chegamos ao momento de entender que as análises desligadas, regredientes, como assim as gostaria de chamar - para usar uma categoria lapidar que César Botella (2007) propõe em seu La figurabilité psychique -, feitas pelo historiador da arte americano seriam, no contexto da experiência com as artes visuais, exemplos críticos tout court: contém em si o gérmen para provocar cortes no jogo de interferências que vai da psicanálise à reflexão estética. Com ferramentas psicanalíticas, Foster arquitetou uma abertura que torna possível pensar o trabalho de recepção em suas conexões mais "primárias" - mas no sentido do processamento primário propriamente dito. Nessa medida, e como espectador de arte, ou seja, entregue ao trabalho de recepção estética, a posição de Foster se apresenta como um antípoda da psicanálise "selvagem" (FREUD, 1996), reconhecidamente violenta e positivista. Acessando a teoria psicanalítica a seu modo, e dela recolhendo o que lhe parece mais apropriado diante do objeto (de arte) a ser investigado, Foster avança no campo da reflexão estética (e da psicanálise!).

Em outro sentido, César e Sára Botella (2007, p. 235-238) indicam, em termos psicanalíticos, a existência de uma "confrontação simultânea" entre os diferentes processos psíquicos, tensão diante da qual a psicanálise recente se vê compelida a dizer algo: se as relações de causalidade conseguem se abster da temporalidade linear; então, a simultaneidade "entre sonho e pensamento diurno; entre desdobramento alucinatório e memória; entre o negativo do trauma infantil e o trabalho de figurabilidade" poderá se instalar numa realidade psíquica singular, isto é, entre aquelas de "predominância representacional" e de predominância "processual" (grifos meus), aliás, bastante apropriadas, a meu ver, para um bom entendimento da arte que costumamos chamar de contemporânea.

\section{Referências}

BENJAMIN, W. Magia e técnica, arte e política: ensaios sobre literatura e história da cultura. São Paulo: Brasiliense, 1994. (Obras escolhidas, v. 1).

BOTELLA, C. e S. La figurabilité psychique. Paris: In Press, 2007.

BUCHLOH, B. The primary colors for the second time. Cambridge: MIT Press, 1986. v. 37.

FOSTER, H. Postmodernism in parallax. October, Cambridge, v. 63, 1993.

The return of the real: the avant-garde at the end of the century. Cambridge: MIT Press, 1996.

FRAYZE-PEREIRA, J. Arte, dor: inquietudes entre estética e psicanálise. Cotia: Ateliê, 2005.

FREUD, S. Sobre el psicoanálisis "silvestre". Buenos Aires: Amorrortu, 1996. (Obras completas, v. 11)

GREEN, A. $O$ desligamento: psicanálise, antropologia e literatura. Rio de Janeiro: Imago, 1994.

KRISTEVA, J.Pouvoirs et limites de la psychanalyse II: la révolte intime. Paris: Fayard, 1997.

LACAN, J. $O$ seminário: os quatro conceitos fundamentais da psicanálise. Rio de Janeiro: Zahar, 1998. v. 11.

LAPLANCHE, J. Problemáticas III: a sublimação. São Paulo: Martins Fontes, 1989.

LAPLANCHE, J.; PONTALIS, J.-B. Vocabulário da psicanálise. Rio de Janeiro: Imago, 2004.

LIU, C. To catch a falling star: Lacan Meets Warhol. Philadelphia: Slought Foundation, (audio) 76 min. 2002. Disponivel em: $<$ http://slought.org/ content/11057>. Acesso em: 21 fev. 2010.

ZYGOURIS, R. Pulsões de vida. São Paulo: Escuta, 1999. 